Katarzyna Borzucka-Sitkiewicz, Katarzyna Kowalczewska-Grabow Poland

\title{
Health Promoting Schools in Poland: an Evaluation of Health Promotion Implementation at Schools with a National Certificate
}

DOI: 10.15804/tner.2018.53.3.02

\begin{abstract}
The 'Health Promoting School' model provides a framework for school-based health promotion (HP) activities, which have become a major theme in the health and educational strategy in Europe. However, the issue of HP implementation is complex. The general purpose of this article is to report on the findings of a nationwide survey that examined the extent of HP implementation at schools in Poland. The research results presented in this paper are part of a broader research project which was conducted at the University of Silesia in Katowice (Poland) in cooperation with the University of Limerick (Ireland). The research was conducted by means of the questionnaire: "National Questionnaire on SPHE and Health Promoting Schools", developed by the staff of the University of Limerick and adapted to Polish conditions. The questionnaires were sent to schools in Poland holding the National Health Promoting School (HPS) Certificate, one hundred and three of which were completed and returned and then analysed with respect to quantity and quality. Considering the theoretical assumptions of the idea analysed, the information obtained from the respondents describing health promotion at their schools was grouped into four categories: school environment; core curriculum and learning; partnership; policy and planning. It was determined that the work of these schools emphasises mostly two elements in building a health promoting school: the school environment along with core curriculum and learning, while the two other elements (partnership; policy and planning) are more poorly implemented.
\end{abstract}

Keywords: health promoting schools, health education, health promotion coordinators, evaluation 


\section{Introduction}

The 'Health Promoting School' model provides a framework for widely accepted school-based health promotion activities, which have become a major theme in health and educational strategy (Inchley et al., 2006). The concept of a health-promoting school (HPS) was first identified in the early 1980s and emerged to be an effective approach in promoting health in schools in the following decades (Lee et al., 2005). In 1992 three international organisations: WHO - Regional Office for Europe, the Council of Europe and the European Commission took the decision to form the European Network of Health Promoting Schools, which adopted an eco-holistic school model suggested by Parsons et al. The model assumed the existence of five interwoven key elements "inside" a school:

1. management, planning and division of roles related to health promotion,

2. cooperation with other organisations, families and the community,

3. curriculum including health education,

4. social and physical environments supporting health promotion,

5. feelings, attitudes, competences and behaviours of the entire school community which are conducive to health (WHO, 1997; Glenddie, 2011).

The HPS concept has enabled health issues to be addressed in more effective and empowering ways (Young, 2005). As St Leger claims, 'school programs that are integrated, holistic and strategic appear to produce better health and education outcomes than those which are mainly information based and implemented only in the classroom' $(2005$, p. 145). Elements forming a health promoting school depend on external factors related to legislation, politics and activities undertaken in the health and education sectors, at international, national, regional and local levels. Therefore, there is a belief that initiatives for forming health promoting schools will not be effective unless supported by local communities and by both the Ministry of Education and the Ministry of Health. The concept initiators, aware of diverse political, economic or cultural circumstances in various countries, allow country specific models to be created.

In Poland, the network structure of health promoting schools has three levels: regional, district or municipal networks, which function at level 1, province networks constitute level 2, while level 3 is the national network. The structure defined in such a manner is vertical in nature (bottom-up type). Every educational establishment may apply to be accepted to the network once four standards defined by the national coordinator of the HPS network are met:

1. The concept of school operations, its structure and organisation should be favourable to the school community's participation in the implementation 
of tasks related to health promotion and to the efficient and long term effects of such activities.

2. The aim of the social climate developed within a school is to support the health and well-being of students, teachers and other school staff as well as the students' parents.

3. The school should implement a health education and prevention programme for students, teachers and other school staff as well as pursue the improvement of its effectiveness. The conditions and organisation of learning and working in the school should be conducive to the health and well-being of students, teachers and other school staff, as well as enhance cooperation with parents (Centre for Education Development, 2016).

In Poland, schools more and more often attempt to be accepted to the HPS network by raising their standards and implementing health ethos in their schools. Currently, 3,000 educational establishments are associated with the HPS network in Poland. An important organisational element in the preparatory period preceding joining the network is the appointment of a school coordinator for the project, who will initiate activities promoting health in the educational establishment and form a team for health promotion.

\section{Methodology}

The research results presented in this paper are a part of a broader research project which was conducted at the University of Silesia in Katowice (Poland) in cooperation with the University of Limerick (Ireland). The aim of the project was to diagnose the implementation of health promotion and health education at schools. The objective of the presented part of the research was to answer the question: What is the course of the implementation of health promotion at schools participating in the research?

The researchers used a diagnostic survey. It was conducted by the questionnaire: "National Questionnaire on SPHE and Health Promoting Schools", developed by the staff of the University of Limerick (Moynihan et al., 2016) and adapted to Polish conditions. The questionnaires were sent to schools in Poland holding the national HPS certificate, one hundred and three questionnaires were completed and returned and then analysed with respect to quantity and quality. The Statistica 12 programme was used to develop quantitative data.

In Poland, the teachers performing the function of coordinators for health promotion at individual educational establishments were the addressees of the 
distributed questionnaires. All the schools participating in the research were state schools. Sixty-six respondent coordinators (64.08\%) indicated that their schools had belonged to the HPS network for over ten years, thirty-three of them (32.04\%) indicated a period from five to ten years, and only three respondents (2.91\%) declared that their school had belonged to the network for fewer than five years.

\section{Findings}

With respect to the literature on the subject, we may assume that a health promoting school creates conditions and initiates activities conducive to the well-being of the members of the school community, by undertaking activities for their own health, and those of others as well as by creating a healthy environment (Parsons et al., 1996). It is also significant that introducing health promotion in schools is not limited to the execution of the curriculum, but it relates to all school activities. With such a perception, we may talk about the ethos of health in schools. An important element of the concept is also cooperation with parents and the local community, which stand behind the intensification of the content learnt at school by students (Moon et al., 1999). In order for the picture of implementing the concept of a health promoting school in Polish conditions to become most complete, all of these elements become the subject of analysis in the research.

The respondents participating in the research were requested to describe health promotion at their schools in the form of an open statement. Out of one hundred the three coordinators, ninety-six provided such answers. Considering the theoretical assumptions of the idea analysed and the standards of a health promoting school as well as the areas suggested in the National Guidebook for Health Promoting Schools (Health Service Executive, 2014), the information obtained from the respondents describing health promotion at their schools was grouped into four categories and interpreted in the following manner:

1. School environment - an environment conducive to the health, safety and well-being of students and all the staff is created at health promoting schools.

2. Core curriculum and learning - health promoting schools aim to achieve goals and implement tasks specified in the general educational core curricula and other binding legal acts. At the same time, the health education of students and staff is implemented with the aim to increase its quality and effectiveness. 
3. Partnership - at health promoting schools, health promoting projects are managed in a manner conducive to participation, partnership and cooperation.

4. Policy and planning (school policy, also concerning curriculum execution) - health promoting schools implement standards and plans long term activities on the grounds of a needs diagnosis.

As observed, the respondents have knowledge on how to create conditions and initiate activities related to health promotion at schools. Considering the above categories, an analysis of the respondents' statements, with some of them quoted, can be found below.

With regards to the school environment, the respondents indicated that the educational establishments participating in the research ensure a good climate by creating work-and-learning-friendly conditions. According to the respondents' declarations, a friendly atmosphere is present at the schools involved in the research, therefore everyone enjoys being there: parents, students, teachers as well as the non-teaching staff. The schools are presented as safe places promoting ecologically-friendly behaviours. A good climate at individual schools contributes to a decrease in school stress and a reduction in aggressive behaviour and violence. As one respondent emphasised: "Health promotion at our school includes, but is not limited to, the creation of appropriate relations between all the people working and learning at the school. We have managed to establish a good rapport, a nice atmosphere and tolerance, which boost teaching and learning efficiency". In their statements, only a few respondents paid attention to the physical environment of the school, which may suggest that changing school equipment in accordance with health promoting principles is more difficult than building a pro-health social environment, because it requires capital.

The respondents' statements on the core curriculum and learning focused on the manner of health education implementation. The respondents emphasised that their educational establishments actively developed towards promoting the healthy mental and physical lifestyle of the entire school community. Furthermore, the education and prevention programme complies with health promotion principles. Its implementation takes place throughout the school year, in several subjects and by various teachers, as necessary. Additionally, the schools run numerous pro-health extracurricular activities such as: interest groups, trips, bike trips, other sports events, festivals, excursions or ecological projects. One coordinator described the scope of topics of activities undertaken at their school in the following way: "Health promotion at our school includes: expanding knowledge about healthy nutrition, balanced diet, physical activity; awareness of hazards caused by stimulants: cigarettes, 
alcohol, designer drugs; raising awareness of hazards for the young person's bodyanorexia, bulimia, obesity; promoting healthy living". The respondents' statements also indicated the effectiveness of activities undertaken within the health education area, e.g.: "Eating habits have improved. Students are more keen on bringing wholemeal bread and salads as their snack, they drink mineral water and tea. (...) We have observed an increase in physical activity among students and their parents. They spend more time doing sports: fitness, jogging, Nordic walking, table tennis, football, etc." Therefore, as the collected data indicates, schools do not limit their activities to the implementation of the core curriculum but also undertake many additional initiatives related to health promotion and shaping a pro-health lifestyle.

Partnership was the issue least mentioned in the respondents' statements. The coordinators who recognised it emphasised the cooperation of individual members of the school community, namely teachers, students, parents and non-teaching staff in the implementation of the health promotion concept. At the same time, the respondents stressed cooperation with institutions functioning in their local community: "We are spreading in the local environment the knowledge on the manner of caring for the health of our students, staff and parents. We implement pro-health tasks in cooperation with associations, organisations and institutions within the local community"; "For years we have run a range of tasks mobilising our schools' students and the local environment to work; we promote ecological actions, we cooperate with various institutions and the Arka foundation...". Therefore, the data obtained indicates that the partnership requirement is recognised in the activities of the educational establishments participating in the research, however, not as often as the two previous ones.

Analysis of the policy and planning at the health promoting schools showed that the respondents also accentuated these issues slightly less frequently than school environment and curriculum. They emphasised that health promotion boils down to planned and regular activities of the entire school community for raising health awareness. In the respondents' opinions, such activities should include creating a work plan based on a starting point diagnosis and then on the implementation and evaluation of a plan developed in such a manner. Moreover, the respondents frequently stressed the fact that the implementation of health promotion requires creating an appropriate organisational structure in school, where the key role should be played by the coordinator and the team for health promotion. The comprehensive quotation, which exemplifies most of the statements made by the respondents, is presented below:

"The school engages in health supporting activities; they are initiated by a School Team for Health Promotion on the grounds of a starting point diagnosis, which 
results in a list of problems. Then the team, in agreement with the School Head Teacher, selects a priority problem to be solved in a given year (the OBJECTIVE), then the team develops an action plan, indicating tasks which will foster elimination of the causes of problems. Such an action plan must be approved by parents and teachers. Activities supporting health are initiated mainly by the School Team for Health Promotion and teachers. The school gets involved in health promoting activities through the implementation of an action plan created by the Team for Health Promotion. The team members conduct self-evaluation, and introduce changes to the activities."

Among the answers, there were also general statements such as: "Health promotion at our school is a priority", "it is top quality", "we introduce one or two priority tasks every school year", "involves all school groups and the local environment", "occasionally", "implemented in accordance with the Health Promoting Programme (available on the website)", which are difficult to classify into one of the above-mentioned categories. Only seven respondents provided no answer to this question at all.

The issue of a school implementing a specific policy promoting healthy living was mentioned additionally in a closed question, due to its importance for the introduction of the HPS idea into school practice. As observed, ninety-nine coordinators (96.12\%) admitted that a policy promoting healthy living was initiated for implementation at their schools. Only three respondents (2.91\%) were not certain about that issue, one person replied that such a policy had not been introduced at her facility. At the same time, all the coordinators declared that a team for health promotion was appointed at their schools (which is a condition to have the certificate awarded). The answers received were a confirmation of the data obtained earlier through an open question regarding the existence of a structure supporting health promotion in schools participating in the research.

\section{Discussion}

Popularisation of health promoting schools is particularly important in the modern world, where there is a prevalence of health hazards and problems such as unhealthy lifestyles, pathologies or high indicators of morbidity and mortality, etc. (Davies and Cooke, 2007). Appropriate preparation of the young generation for caring for their health and the health of their immediate environment by qualified teachers will bring the expected results in a long-term perspective. Therefore, it is worth emphasizing that the last thirty years have seen an increase in many 
publications identifying the effects of promoting health in schools (McNamara et al., 2010), but there is still a need for further evaluation of and research on the concept of health-promoting schools and factors enhancing or inhibiting health promotion in school settings (Turunen et al., 2004).

Comparison of the data obtained with the Irish data may indicate certain similarities. In both countries the work of schools emphasises mostly two elements building a health promoting school: the environment as well as core curriculum and learning, while the implementation of the two other elements is slightly poorer (partnership as well as policy and planning), even though most Polish coordinators are familiar with the correct structure of a health promoting school. What may seem to be a paradox considering the resources, the position of Poland is slightly better in this juxtaposition - in Ireland, teachers complain more often about limited opportunities of implementing health education in the curriculum and school practice, and problems related to implementing the idea of the entire school community's participation in health promoting activities seem to be bigger. This may be caused by the fact that all post-primary schools in Ireland were included in the research, while in Poland only schools holding the National Certificate of HPS participated in the survey.

The research carried out reveals that the holistic content within the scope of health education is implemented at most health promoting schools, however topics related to social relationships and sexuality are marginalised. At most schools, health education content is implemented in many subjects and a special subject related to health education was created additionally at nearly $12 \%$ of the schools, which is perceived as a very beneficial solution. Devoting additional time and space to health education in a school's organisation allows students to understand the significance of the issues discussed and in further perspective it may be the cause of significant changes to their knowledge and skills.

As declared by the coordinators in over $95 \%$ of the health promoting schools, a health promoting programme has been developed. Surprisingly, the remaining percentage of the respondents failed to provide an answer or had no opinion regarding that subject. Only schools holding the Certificate of National Network of Health Promoting Schools participated in the research and one of the conditions of receiving the certificate is to develop their own health promoting programme with the assumption that health education is a tool for promoting health. Presumably, knowledge deficits in the case of some respondents are the effect of their lack of interest in performing the function of a coordinator, which may be the result of the fact that they were appointed by the school head teachers to perform this function and had not volunteered for it. At the same time, it needs 
to be highlighted that $96 \%$ of the coordinators are convinced of the significance and value of health education and most of them are deeply involved; they perform their functions for the community and are truly devoted to the idea of health promotion and health education. They attempt - to the extent the available funds allow - to implement it in the school's daily life, despite obstacles of both social and institutional nature.

However, the conducted research allowed us to indicate several areas which require further work on the implementation of the concept of health promoting school in Polish conditions. These areas include the involvement of parents and the local community in activities undertaken by the school, a holistic approach to the implemented content or provisions of essential human resources and materials for health promotion implementation at school. Similar issues were pointed out in the Irish research - the respondents there outlined a range of individual themes implemented in schools such as substance use, anti-bullying, healthy eating, but the existence of a coherent HPS policy under which these themes could be addressed was lacking. Parents were visible in only $2 \%$ of the responses concerning school activities and descriptions of more meaningful partnerships with the local community were limited and were clearly an area requiring more support (Moynihan et al., 2016).

To sum up, both in Poland and in Ireland, schools appeared to demonstrate success in some areas but less so from the whole school perspective. This may suggest that school implementation can be seen as problematic. For more effective implementation of health promotion from the whole school perspective, national educational policies need to conceptualise the whole school approach more clearly. Taking into consideration the diversity of health promotion practices among schools, outlining specific indicators for each HPS component would be helpful (Moynihan et al., 2016). Moreover, schools need strong organizational and material support in their endeavours to become health promoting schools.

This study confirms the results obtained in other evidence-based research indicating that school health promotion can have positive outcomes (Stewart-Brown, 2006; Gleddie, 2011), but its implementation is a complex endeavour and for this reason has not yet been successful on a broad scale (Guggleberger, 2011). Furthermore, as indicated by Keshavarz et al. (Keshavarz et al., 2010; Guggleberger, 2011), there are no appropriate rules on how to properly support schools in becoming health promoting ones so far, which is an important issue in the context of capacity building. 


\section{Acknowledgements}

The authors would like to thank Sharon Moynihan, Didier Jourdan and Patricia Mannix McNamara for permission to use and adapt their research tool, as well as share the results of the Irish research.

\section{Refrences}

Davis, J.M., Cooke, S.M. (2007). Educating for a healthy, sustainable word: an argument for integrating Health Promoting Schools and Sustainable Schools. Health Promotion International, 22, 346-353.

Gleddie, D. (2011). A journey into schools' health promotion: district implementation of the health promoting schools approach. Health Promotion International, 27, 82-89.

Gugglberger, L. (2011). Support for health promoting schools: a typology of supporting strategies in Austrian provinces. Health Promotion International, 26, 447-456.

Health Service Executive (2014). Schools for health in Ireland: framework for developing Health Promoting Schools. www.healthpromotion.ie. ( last accessed 21 March 2014)

Inchley, J., Muldoon, J. and Currie, C. (2006) Becoming a health promoting school: evaluating the process of effective implementation in Scotland. Health Promotion International, 22, 65-71.

Keshavarz, N., Nutbeam, D., Rowling, L. and Khavarpour, F. (2010). Schools as social complex adaptive systems: a new way to understand the challenges of introducing the health promoting schools concept. Social Science \& Medicine, 70, 1467-1474.

Lee, A., Cheng, F.F., and St Leger, L. (2005). Evaluating health-promoting schools in Hong Kong: development of a framework. Health Promotion International, 20, 177-186.

McNamara, P.M., Geary, T. and Jourdan, D. (2010). Gender implications of the teaching of relationships and sexuality education for health-promoting schools. Health Promotion International, 26, 230-237.

Moon, A.M., Mulle, M.A., Rogers, L., Thopmson, R.L., Speller V. and Roderick, P. (1999). Helping schools to become health-promoting environments - an evaluation of the Wessex Healthy Schools Award. Health Promotion International, 14, 111-122.

Moynihan, S., Jourdan, D., McNamara, P.M. (2016). An examination of Health Promoting Schools in Ireland. Health Education 116, 16-33.

Parsons, C., Stears, D. and Thomas, C. (1996). The health promoting school in Europe: Conceptualising and evaluating the change. Health Education Journal, 55, 311-321.

Stewart-Brown, S. (2006) What is the Evidence on School Health Promotion in Improving Health or Preventing Disease and, Specifically, What is the Effectiveness of the Health Promoting Schools Approach? World Health Organization Regional Office for Europe, Copenhagen.

St. Leger, L. (2005). Protocols and Guidelines for Health Promoting Schools. Promotion and Education, XII, 145-150.

Turunen, H., Tossavainen, K., Verito, H. (2004). How can critical incidents be used to 
describe health promotion in the Finnish European Network of Health Promoting Schools? Health Promotion International, 19, 419-427.

WHO. (1997). Promoting Health Through Schools. Report of a WHO Expert Committee on Comprehensive School Health Education and Promotion. World Health Organization Technical Report Series 870, Geneva.

Young, I.(2005). Health Promoting in Schools: a historical perspective. Promotion and Education XII, 112. 